Research Paper:

\title{
Investigation and Optimization of Air Pollution Risk by a Multi-criteria Decision Making Method Using Fuzzy TOPSIS: A Case Study of Construction Workers
}

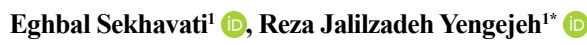 \\ 1. Department of Environmental Engineering, Ahvaz Branch, Islamic Azad University, Ahvaz, Iran.
}

\begin{tabular}{|c|c|}
\hline $\begin{array}{l}\text { Use vour device toscan } \\
\text { and read the article online }\end{array}$ & \multirow{3}{*}{$\begin{array}{l}\text { Citation Sekhavati E, Jalilzadeh Yengejeh R. Investigation and Optimization of Air Pollution Risk by a Multi-criteria Deci- } \\
\text { sion Making Method Using Fuzzy TOPSIS: A Case Study of Construction Workers. Journal of Advances in Environmental } \\
\text { Health Research. 2021; 9(4):265-276. http://dx.doi.org/10.32598/JAEHR.9.4.1229 }\end{array}$} \\
\hline 口保茴 & \\
\hline $4+48$ & \\
\hline 口ifing & doi): http://dx.doi.org/10.32598/JAEHR.9.4.1229 \\
\hline
\end{tabular}

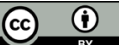

Article info:

Received: 10 Apr 2021

Accepted: 23 Aug 2021

Publish: 01 Oct 2021

\section{Keywords:}

Risk assessment, MODM, Fuzzy TOPSIS,

Air pollution risk, Construction workers

\begin{abstract}
A B S T RAC T
Background: Investigating human health during work importantly affect the safety and efficiency of the society. Different types of activity, including industrial, constructional, heavy duty ones, etc., affect the health of workers during their activities. In this study, the Multi-Objective DecisionMaking (MODM) method was combined with fuzzy TOPSIS to investigate and optimize the air pollution risk affecting the health and safety of construction workers of Lar City, Fars Province, Iran.

Methods: The comparison matrices (binary) and the Phillips-Perron test of different criteria and sub-criteria of health risk, including safety view, safety efficiency, understanding the risk, and risk investigation, were assessed to find the most influential factors for the optimization of the health risk of the workers.

Results: Accordingly, the results indicated that "understanding the risk" followed by "safety efficiency" affected the health risk of the construction workers the most. However, among the sub-criteria, the most effective ones were "worker knowledge", "manager knowledge", "logistic specialized managers", "modern facilities", and "modern technology". The selection of the linear and non-linear models was conducted according to the $\mathrm{F}$ values, and the model parameters were estimated using the Newton-Raphson test. Most coefficients were significant at $\mathrm{P}=0.99$. The model also has a high describing value of 0.97 . The final estimated homogeneity coefficient was equal to 1.31 , and it ranged from 0.86 to 2.72 for the critical risk investigation. The significance of the present research is to increase the health and safety of workers during work resulting in a more sustainable and healthier environment.
\end{abstract}

Conclusion: Accordingly, the managers could handle the risks, determine the tolerable risks, indicate the risk of each process to control expenses, and take the essential measures for optimization.

\footnotetext{
* Corresponding Author:

Reza Jalizadeh Yengejeh, $P h D$.

Address: Department of Environmental Engineering, Ahvaz Branch, Islamic Azad University, Ahvaz, Iran.

Phone: +98 (912) 4794322

E-mail:r.jalilzadeh@iauahvaz.ac.ir
} 


\section{Introduction}

I

nvestigating human health during work significantly affects the safety and efficiency of society. Different activities, including industrial, constructional, heavy-duty ones, etc., affect workers' health during their activities. Among the most important factors, which may affect the health of the construction workers during work is air pollution. Accordingly, if the environment is optimized to decrease any type of health risk, it would be possible to increase the safety of the society and reduce the expenses, which may be required for the repair of the related damages resulting from different activities $[1,2]$.

Multi-Criteria Decision-Making (MCDM) methods are divided into two categories: the Multi-Objective Decision Making (MODM) and Multi-Attribute Decision Making (MADM). The purpose of decision-making is to choose the best option or weigh the decision factors. Each decision-making method has a specific task: one is the goal of weighting the criteria, one is to rank the options, and the other is to evaluate the criteria.

Different methods have been suggested to find the damage caused by different activities and subsequently find the solutions, which may decrease such types of damages in the society, and contribute to increasing people health [3]. The use of the MODM method is among the newest ones, which may solve such issues [4].

If at the time of making decisions, several goals are considered, the use of multi-purpose objectives in the MCDM method is helpful [5]. Accordingly, among the main objective of using MODM is to prioritize the conditions of risk, so it would be possible to take the most efficient measures, controlling tools, and optimizations methods for the more safety of industrial environments [6].

The objectives of minimizing the expenses and maximizing quality and efficiency may significantly improve the responses and precision of such methods. Because of society's need for decision-making methods and the development of different instruments, including computers, decision-making methods have been considerably enhanced [7, 8].

However, because researchers have not yet found a suitable method to investigate and optimize health risk during work, fuzzy TOPSIS (a technique for order preference by similarities to ideal solution) as a logical, systematic, and developing method with MODM has been suggested. Additionally, because of the association of uncertainty with MODM, fuzzy TOPSIS may be used to decrease such uncertainty for the investigation and ranking of health risks [9-11].

TOPSIS is extensively used for ranking the alternatives and finding the most suitable choices. It can easily attach the relative significance of attributes and the impact of alternatives to numerical measures [12]. TOPSIS can combine the quantitative and qualitative parameters to optimize health risk, express the priority of choices quantitively, indicate the differences and the similarities of indexes, compare the criteria of decision-making methods in terms of expenses, simplicity, usefulness, rate of operation, and specification, and be a complete method for ranking the alternatives. Fuzzy TOPSIS investigates $m$ choices with $n$ criteria. If different criteria have more variables, they are of higher significance and also have higher weights [13-15].

With respect to what was discussed and the significance of providing a healthy and safe environment for the workers, the present research was conducted to optimize the health risk of air pollution for the construction workers of Lar City, Fars province, Iran using MODM and fuzzy TOPSIS.

\section{Materials and Methods}

\section{Collection of data}

The statistical population consisted of all construction workers and employees in the health bureau of Lar City (Figure 1). The first stage of the research (description part) was conducted by questioning 100 construction workers to investigate their current situation, the initial levels of air pollution risk, and the workers understanding of air pollution, health risks, safety view, safety efficiency, controlling measures, the proper methods of performing the work, and the like. Using the comparison matrices (binary) of the main criteria and sub-criteria, and the Phillips-Perron root test, the significance of each variable in affecting the health risk potential of the construction workers, was determined.

The second stage of the research was qualitative. We used fuzzy TOPSIS in a multi-objective decision-making environment to optimize the health risk potential of air pollution. Accordingly, following the first stage of the research, 15 professional health employees of the health bureau were selected by interviewing and questioning. They investigated, prioritized, and optimized the risks using the MODM method and fuzzy TOPSIS. 


\section{Sampling}

The minimum number of sampling for the first stage (quantitative) was calculated 100 considering the objectives of the design, type, and research method, with the effect size of $20 \%$, the power of $80 \%$, and the confidence interval of $95 \%$. The samples were randomly selected among the construction workers using the Equation 1:

$$
\text { 1. } n^{\prime}=\frac{\left(z_{1 \frac{\alpha}{2}}+z_{1-\beta}\right)^{2}}{\frac{d}{(2 \delta)^{2}}}
$$

Here, $n$ ' is the size of the sample, $\mathrm{Z}$ is the tabulated value for the normal distribution of the desired confidence level, $\sigma$ is the standard deviation of the output, and $\alpha$ and $\beta$ are the coefficients of the formula.

\section{Multi-criteria Decision Making (MCDM) and TOPSIS Fuzzy}

The Technique for Order Performance by Similarity To Ideal Solution (TOPSIS) was first invented by Hwang and Yoon (1981). It is a classic method for solving the problem of MCDM. However, because of the association of uncertainty with such type of decision making, it was combined with fuzzy TOPSIS. The basis of the TOPSIS concept is to have the maximum distance from the negative optimum solution and the minimum distance from the positive optimum solution. The performance of the TOPSIS process is determined by the ratings and the criteria weights defined by crisp values.

The present research intended to extend the TOPSIS method into the fuzzy environment because crisp values sometimes may not be suitable to model a natural phenomenon. In fact, it is not always possible to indicate the preferences of vague human decision-making solutions by crisp values. Accordingly, the combined use of TOPSIS with fuzzy method has been suggested for solving such issues by using the linguistic variables, which determine the weights and ratings of the alternatives. The method of TOPSIS fuzzy has been used because the relative significance of different factors in the decisionmaking people is not the same. Accordingly, the most optimized choice has to be selected.

A fuzzy TOPSIS uses the following stages for the conclusion of an issue: 1) finding the average matrix, 2) solving the initial matrix for the normalized axes, 3) solving the total matrix, and 4) indicating the critical value and the role of the network of activities.
The definition of a standard fuzzy TOPSIS is according to the Equation 2:

$$
\text { 2. } t=\Phi^{\prime} \mathrm{Zt}+\left(\Theta^{\prime} \mathrm{Zt}\right) \mathrm{G}(\mathrm{St}, \mathrm{y} \mathrm{c})+\mathrm{Ut} \text {, }
$$

in which $\Phi^{\prime}$ is the vector of linear parameters, $\Theta^{\prime}$ is the vector of non-linear parameters, and $\mathrm{Zt}$ is the vector of internal variables.

The model is evaluated with graphical analyses using different tests, including correlated errors, a test of no remaining nonlinearity, parameter constancy test, etc. Accordingly, the model is estimated according to the following stages: 1) developing a linear model (autoregressive [AR]), 2) testing the nonlinearity of the model, 3) selecting the variable, 4) selecting the model (Logic Fuzzy TOPSIS or Technique for Order of Preference by Similarity to Ideal Solution [TOPSIS]), 5) selecting the right initial values for $\gamma$ and $\mathrm{c}$ in the Newton-Raphson algorithm, 6) estimating the final model using the algorithm and maximum likelihood estimation, and 7) testing the model.

\section{Statistical analysis}

The quantitative statistical analysis of data was conducted in SPSS version 21. Also, the optimization of the health risk of construction workers by air pollution in an MODM environment was done using LINGO software.

\section{Results and Discussion}

\section{Main criteria and sub-criteria affecting health risk}

The investigated parameters, including safety view, safety efficiency, understanding the risk, and risk investigation affecting the optimization of health risk in the environment, are presented in Figure 2. Accordingly, such criteria were categorized into the following sub-criteria: A) safety view, including 1) modern facilities, 2) modern technology, 3) system for advanced repairing, and 4) finding the suitable location; B) safety use, including 1) manager proficiency, 2) manager knowledge, and 3 ) manager experience; C) safety understanding, including 1) workers proficiency, 2) workers knowledge, and 3) workers experience, and D) risk investigation, including 1) logistic specialized employees, 2) logistic specialized managers, and 3) logistic facilities.

\section{Comparison matrices}

The comparison matrices of the main criteria are presented in Table 1. The results indicated the main criteria of "understanding the risk", followed by "safety ef- 
Table 1. The correlation (binary) of the main criteria of the health risk

\begin{tabular}{|c|c|c|c|c|c|}
\hline \multirow{2}{*}{ Criteria } & \multicolumn{5}{|c|}{ The Correlation (Binary) of the Main Criteria (Matrix W22) } \\
\hline & Understanding the Risk & Safety Efficiency & Evaluating the Risk & Safety View & Normal \\
\hline $\begin{array}{l}\text { Understanding the } \\
\text { risk }\end{array}$ & 1 & & & & 0.31 \\
\hline Safety efficiency & 0.2 & 1 & & & 0.23 \\
\hline Evaluating the risk & 0.5 & & 1 & & 0.20 \\
\hline \multirow[t]{3}{*}{ Safety view } & 0.33 & & & 1 & 0.16 \\
\hline & \multicolumn{5}{|c|}{ The Correlation (Binary) of the Main Criteria by Controlling "Understanding the Risk" } \\
\hline & Safety Efficiency & Evaluating the Risk & Safety View & Normal & \\
\hline Safety efficiency & 1 & & & 0.35 & \\
\hline Evaluating the risk & 0.5 & 1 & & 0.29 & \\
\hline \multirow[t]{2}{*}{ Safety view } & 0.33 & 0.5 & 1 & 0.22 & \\
\hline & \multicolumn{5}{|c|}{ The Correlation (Binary) of the Main Criteria by Controlling “Understanding the Risk" } \\
\hline $\begin{array}{l}\text { Understanding the } \\
\text { risk }\end{array}$ & 1 & & & 0.35 & \\
\hline Evaluating the risk & 0.5 & 1 & & 0.29 & \\
\hline \multirow[t]{2}{*}{ Safety view } & 0.25 & 0.17 & 1 & 0.16 & \\
\hline & \multicolumn{5}{|c|}{ The Correlation (Binary) of the Main Criteria by Controlling "Evaluating the Risk" } \\
\hline $\begin{array}{l}\text { Understanding the } \\
\text { risk }\end{array}$ & 1 & & & 0.38 & \\
\hline Safety efficiency & 0.33 & 1 & & 0.29 & \\
\hline \multirow[t]{2}{*}{ Safety view } & 0.20 & 0.33 & 1 & 0.19 & \\
\hline & \multicolumn{5}{|c|}{ The Correlation (Binary) of the Main Criteria by Controlling "Safety View" } \\
\hline $\begin{array}{l}\text { Understanding the } \\
\text { risk }\end{array}$ & 1 & & & 0.38 & \\
\hline Safety efficiency & 0.25 & 1 & & 0.28 & \\
\hline Evaluating the risk & 0.17 & 0.25 & 1 & 0.17 & \\
\hline
\end{tabular}

ficiency", and "safety view" obtained the highest rank, and the main criteria of "understanding the risk" affected the indexes of health risk optimization at most. The main criteria were also examined, considering a triple comparison of the main criteria. Accordingly, in the case of omitting the main criteria of "understanding the risk", the main criteria of "safety efficiency", otherwise just like the comparison of all the main criteria, "understanding the risk" had the highest rank (Table 1).

\section{The most effective criteria and sub-criteria}

The compatibility factor indicated the main factor of "understanding the risk", followed by "safety efficiency", had the highest correlation with the other main criteria.
However, among the sub-criteria, "worker knowledge", "manager knowledge", "logistic specialized managers", "modern facilities", and "modern technology" were the most effective ones (Tables 2 and 3). The results also indicated that the different sub-criteria were scientifically correlated (Table 4). According to the Phillips and Perron root test, the main criteria of "understanding the risk" and "safety efficiency" were the most effective variables of the model that significantly affected the health risk potential of the construction workers (Table 5).

\section{Selection of the right model}

The selection of the linear and non-linear (fuzzy TOPSIS) model was conducted according to the F values, and 
Table 2. The correlation (binary) of the sub-criteria of the health risk

\begin{tabular}{|c|c|c|c|c|}
\hline \multirow{2}{*}{ Criteria } & \multicolumn{4}{|c|}{ The Correlation (Binary) of the Main Criteria Using the Compatibility Factor } \\
\hline & Understanding the Risk (C1) & Safety Efficiency (C2) & $\begin{array}{l}\text { Evaluating the } \\
\text { Risk (C3) }\end{array}$ & Safety View (C4) \\
\hline Understanding the risk ( $\mathrm{C} 1$ ) & 0 & 0.35 & 0.38 & 0.38 \\
\hline Safety efficiency (C2) & 0.35 & 0 & 0.27 & 0.25 \\
\hline Evaluating the risk (C3) & 0.29 & 0.29 & 0 & 0.19 \\
\hline \multirow[t]{2}{*}{ Safety view (C4) } & 0.22 & 0.16 & 0.17 & 0 \\
\hline & \multicolumn{4}{|c|}{ The Correlation (Binary) of the Sub-criteria of "Safety Efficiency" } \\
\hline Sub-criteria & Worker Proficiency (E1) & $\begin{array}{l}\text { Worker Knowledge } \\
\text { (E2) }\end{array}$ & $\begin{array}{l}\text { Worker Experi- } \\
\text { ence (E3) }\end{array}$ & Normal \\
\hline Worker proficiency (E1) & 1 & 0.33 & 2.0 & 0.16 \\
\hline Worker knowledge (E2) & 3.0 & 1 & 3.0 & 0.30 \\
\hline \multirow[t]{2}{*}{ Worker experience (E3) } & 0.5 & 0.33 & 1 & 0.08 \\
\hline & \multicolumn{4}{|c|}{ The Correlation (Binary) of the Sub-criteria of "Safety Efficiency" } \\
\hline Sub-criteria & Workers Proficiency (E1) & $\begin{array}{l}\text { Workers Knowledge } \\
\text { (E2) }\end{array}$ & $\begin{array}{l}\text { Workers Experi- } \\
\text { ence (E3) }\end{array}$ & Normal \\
\hline Manager proficiency (EC1) & 1 & 0.33 & 2.0 & 0.28 \\
\hline Manager knowledge (EC2) & 3.0 & 1 & 3.0 & 0.47 \\
\hline Manager experience (EC3) & 0.5 & 0.33 & 1 & 0.16 \\
\hline
\end{tabular}

The correlation (binary) of the sub-criteria of "risk investigation"

\begin{tabular}{|c|c|c|c|c|c|}
\hline Sub-criteria & $\begin{array}{l}\text { Logistic Specialized Employ- } \\
\text { ees (P1) }\end{array}$ & $\begin{array}{l}\text { Logistic Specialized } \\
\text { Managers (P2) }\end{array}$ & $\begin{array}{l}\text { Logistic Facilities } \\
\text { (P3) }\end{array}$ & \multicolumn{2}{|c|}{ Normal } \\
\hline $\begin{array}{l}\text { Logistic specialized em- } \\
\text { ployees (P1) }\end{array}$ & 1.0 & 0.33 & 2.0 & \multicolumn{2}{|l|}{0.07} \\
\hline $\begin{array}{l}\text { Logistic specialized manag- } \\
\text { ers (P2) }\end{array}$ & 3.0 & 1 & 3.0 & \multicolumn{2}{|l|}{0.28} \\
\hline \multirow[t]{2}{*}{ Logistic facilities (P3) } & 0.5 & 0.33 & 1.0 & 0.19 & \\
\hline & \multicolumn{5}{|c|}{ The Correlation (Binary) of the Sub-criteria of "Safety View" } \\
\hline Sub-criteria & Modern Facilities (S1) & $\begin{array}{l}\text { Modern Technology } \\
\text { (S2) }\end{array}$ & $\begin{array}{l}\text { System for Ad- } \\
\text { vanced Repairing } \\
\text { (S3) }\end{array}$ & $\begin{array}{l}\text { Finding the } \\
\text { Suitable Lo- } \\
\text { cation (S4) }\end{array}$ & Normal \\
\hline Modern facilities (S1) & 1.0 & 2.0 & 2.0 & 5.0 & 0.36 \\
\hline Modern technology (S2) & 0.5 & 1.0 & 3.0 & 5.0 & 0.32 \\
\hline $\begin{array}{l}\text { System for advanced } \\
\text { repairing (S3) }\end{array}$ & 0.5 & 0.33 & 1.0 & 2.0 & 0.10 \\
\hline $\begin{array}{c}\text { Finding the suitable loca- } \\
\text { tion (S4) }\end{array}$ & 0.2 & 0.2 & 0.5 & 1.0 & 0.06 \\
\hline
\end{tabular}

the model parameters were estimated using the NewtonRaphson test. The variables, which were not significant, were removed from the model (Table 6). Most coefficients were significant at $\mathrm{P}=0.99$. The model also has a high describing value with respect to the high $\mathrm{R}^{2}$ value of 0.97 (Table 7). The final estimated $\gamma$ (homogeneity coefficient) was equal to 1.31 , and ranged from 0.86 to
2.72 for the critical risk investigation. Accordingly, the transfer function is equal to the following:

$\mathrm{G}(1.31, \mathrm{c}$, investigation risk $)=(1+\exp \{-1.31$ (investigation risk $(\mathrm{t})-0.86)($ investigation risk $(\mathrm{t})-2.72)\})^{-1}$ 
Table 3. The combined correlation (binary) of the sub-criteria of the health risk

\begin{tabular}{|ccccc}
\hline Criteria & Understanding the Risk & Safety Efficiency & Risk Investigation & Safety View \\
\hline Worker proficiency & 0.16 & 0 & 0 & 0 \\
\hline Worker knowledge & 0.30 & 0 & 0 & 0 \\
\hline Worker experience & 0.08 & 0 & 0 & 0 \\
\hline Manager knowledge & 0 & 0.47 & 0 & 0 \\
\hline Manager experience & 0 & 0.16 & 0 & 0 \\
\hline Manager proficiency & 0 & 0.09 & 0 & 0 \\
\hline Logistic specialized employees & 0 & 0 & 0.07 & 0 \\
\hline Logistic specialized managers & 0 & 0 & 0.28 & 0 \\
\hline Logistic facilities & 0 & 0 & 0.19 & 0.36 \\
\hline Modern facilities & 0 & 0 & 0 & 0.32 \\
\hline Modern technology & 0 & 0 & 0 & 0.10 \\
\hline System for advanced repair- & 0 & 0 & 0 & 0.06 \\
\hline ing & 0 & 0 & 0 & 06 \\
\hline
\end{tabular}

Table 4. The positive combined correlation (binary) of the sub-criteria of the health risk

\begin{tabular}{|c|c|c|c|c|c|c|c|c|c|c|c|c|c|c|}
\hline Row & Criteria & 1 & 2 & 3 & 4 & 5 & 6 & 7 & 8 & 9 & 10 & 11 & 12 & 13 \\
\hline 1 & Worker proficiency & $*$ & & $*$ & $*$ & $*$ & $*$ & $*$ & & & $*$ & & & \\
\hline 2 & Worker knowledge & $*$ & & $*$ & $*$ & $*$ & $*$ & $*$ & & & $*$ & & & \\
\hline 3 & Worker experience & & $*$ & & $*$ & $*$ & $*$ & $*$ & & & $*$ & & & \\
\hline 4 & $\begin{array}{l}\text { Manager } \\
\text { knowledge }\end{array}$ & & & & $*$ & $*$ & $*$ & $*$ & $*$ & & & & $*$ & \\
\hline 5 & $\begin{array}{l}\text { Manager } \\
\text { experience }\end{array}$ & $*$ & $*$ & $*$ & $*$ & $*$ & $*$ & & & & & & $*$ & \\
\hline 6 & $\begin{array}{l}\text { Manager profi- } \\
\text { ciency }\end{array}$ & & & & $*$ & $*$ & $*$ & & & & & $*$ & $*$ & \\
\hline 7 & $\begin{array}{l}\text { Logistic specialized } \\
\text { employees }\end{array}$ & & & & & & & & & & & & & \\
\hline 8 & $\begin{array}{c}\text { Logistic specialized } \\
\text { managers }\end{array}$ & & & & & & & & & $*$ & & $*$ & $*$ & $*$ \\
\hline 9 & Logistic facilities & & & & $*$ & & $*$ & $*$ & & & $*$ & $*$ & & \\
\hline 10 & Modern facilities & & & $*$ & $*$ & & & & & & $*$ & & & \\
\hline 11 & Modern technology & $*$ & & & & $*$ & & & & & & $*$ & & $*$ \\
\hline 12 & $\begin{array}{c}\text { System for } \\
\text { advanced repairing }\end{array}$ & & $*$ & $*$ & $*$ & $*$ & & & & & & $*$ & & \\
\hline 13 & $\begin{array}{l}\text { Finding the suitable } \\
\text { location }\end{array}$ & & & $*$ & & & & & & & $*$ & $*$ & & \\
\hline
\end{tabular}


Table 5. Philips and Perron Root Test for the model variables

\begin{tabular}{ccc}
\hline Variable & $\mathbf{Y}$ & Y (With Time Series) \\
\hline Safety view & $(0.00)-21.46$ & $(0.00)-21.55$ \\
\hline Risk investigation & $(0.10)-2.54$ & $(0.00)-4.78$ \\
\hline Safety efficiency & $(0.00)-6.01$ & $(0.00)-6.43$ \\
\hline Understanding the risk & $(0.00)-5.05$ & $(0.00)-6.78$ \\
\hline
\end{tabular}

Variables in the brackets indicate the probability of the tested variable.

Table 6. Selecting The Model and the Variables With Respect to the F Values

\begin{tabular}{cccccc}
\hline Variable & F & F4 & F3 & F2 & Suggested Model \\
\hline Safety view $(\mathrm{t}-1)$ & 0.000 & 0.132 & 0.039 & 0.000 & L** fuzzy TOPSIS1 \\
Safety view (t-2) & 0.425 & 0.913 & 0.4 & 0.038 & Linear \\
\hline Risk investigation ( $\mathrm{t}$ ) & 0.000 & 0.041 & 0.000 & 0.000 & Lfuzzy TOPSIS2 \\
\hline Risk investigation (t-1) & 0.003 & 0.592 & 0.032 & 0.000 & Lfuzzy TOPSIS1 \\
\hline Risk investigation (t-2) & 0.371 & 0.653 & 0.927 & 0.01 & Linear \\
\hline Risk investigation (t-3) & 0.023 & 0.367 & 0.256 & 0.001 & Lfuzzy TOPSIS1 \\
\hline Risk efficiency (t) & 0.021 & 0.039 & 0.164 & 0.206 & Lfuzzy TOPSIS1 \\
\hline Risk efficiency (t-1) & 0.01 & 0.369 & 0.003 & 0.122 & Lfuzzy TOPSIS2 \\
\hline Trend & 0.000 & 0.043 & 0.000 & 0.005 & Lfuzzy TOPSIS \\
\hline
\end{tabular}

* Indicates the most suitable suggested variable; ** Logic.
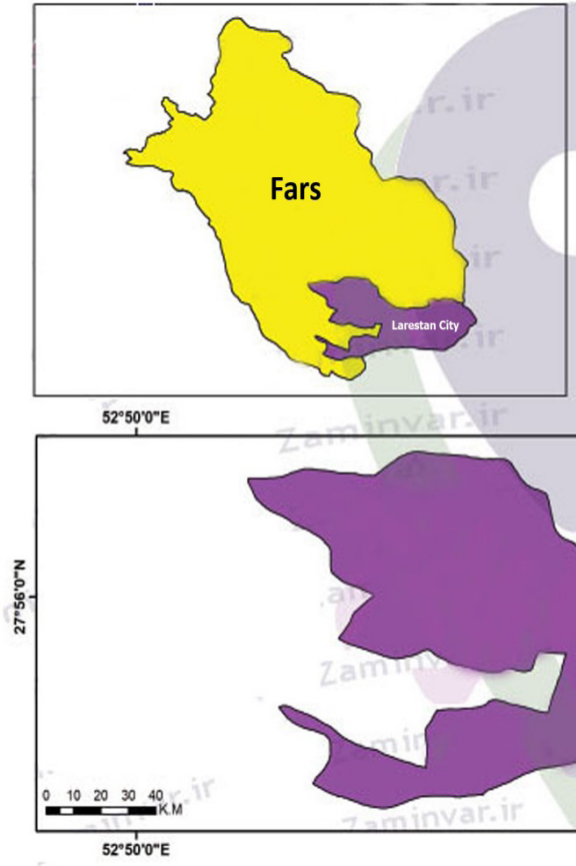

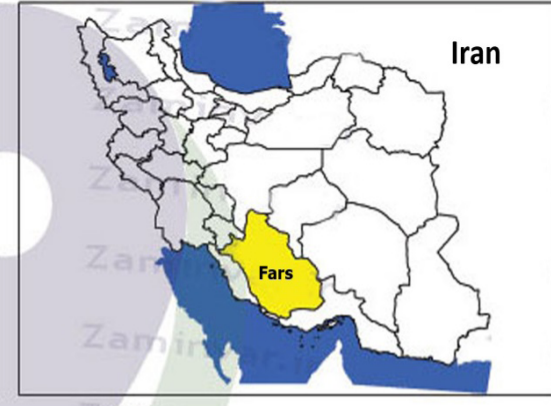

$54^{*} 40^{\circ} 0^{\circ} \mathrm{E}$

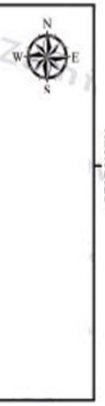

Figure 1. The research area 
Table 7. The final estimation of the model

\begin{tabular}{|c|c|c|c|}
\hline Linear & Coefficient $(\theta)$ & $\mathbf{t}$ & $\mathbf{t}>\mathbf{P}$ \\
\hline Constant & -0.25 & -4.29 & 0.001 \\
\hline Safety view (t-1) & -0.12 & -2.52 & 0.014 \\
\hline Understanding the risk $(\mathrm{t})$ & 0.38 & 2.98 & 0.004 \\
\hline Safety efficiency (t) & -1.28 & -4.63 & 0.000 \\
\hline Understanding the risk (t-1) & 0.78 & 5.67 & 0.000 \\
\hline Safety efficiency (t-1) & 1.5 & 4.38 & 0.000 \\
\hline Understanding the risk ( $\mathrm{t}-2$ ) & 1.38 & 9.16 & 0.000 \\
\hline Risk investigation (t-2) & 0.32 & 8.33 & 0.000 \\
\hline Risk investigation (t-3) & -0.039 & -9.72 & 0.000 \\
\hline \multicolumn{4}{|l|}{ Non-linear } \\
\hline CONST & -0.82 & -1.8 & 0.076 \\
\hline Safety view (t-1) & 2.02 & 2.64 & 0.01 \\
\hline Safety view (t-2) & -1.13 & -1.88 & 0.064 \\
\hline Safety efficiency (t) & 5.78 & 1.95 & 0.056 \\
\hline Risk investigation (t) & 2.45 & -2.89 & 0.005 \\
\hline Understanding the risk (t-1) & 3.16 & 2.3 & 0.024 \\
\hline Safety efficiency (t-1) & -4.11 & -2.7 & 0.009 \\
\hline Risk investigation (t-1) & 0.7 & 1.88 & 0.064 \\
\hline Risk investigation (t-2) & -1.42 & -2.28 & 0.003 \\
\hline Risk investigation (t-30) & 3.4 & 3.03 & 0.003 \\
\hline Akaike Information Criterion & Schwarz Information Criterion & $\begin{array}{c}\text { Hannan-quinn Information } \\
\text { Criterion }\end{array}$ & $\mathbf{R}^{2}$ \\
\hline-6.46 & -5.79 & -6.20 & 0.971 \\
\hline
\end{tabular}

The present research was conducted to investigate and optimize the health risk of air pollution, which may affect the safety and health of construction workers of Lar City. Because of the uncertainty of the MODM, the fuzzy TOPSIS was combined with MODM to find the most effective criteria and sub-criteria on the health of the workers during work. The correlation matrices (binary), singly and combined, were calculated to find the role of each parameter in affecting the health of the workers.

The results indicated that "understanding the risk" followed by "safety efficiency" were the most influential parameters significantly determining the health risk of the workers. Accordingly, the higher the understanding of the workers from the health of the environment, the higher the safety during the work can be $[16,17]$. If the workers know the health risk precisely, they could treat it more efficiently and take the proper measures to handle it [18]. Such safety can be achieved through different means, including the proper instruction of the workers, their higher knowledge (sub-criteria) of the work and the environment surrounding them, and the proper use of modern technology and facilities (sub-criteria) [19, 20]. "Safety efficiency" is also the second most important parameter affecting the workers' health during work. The more efficient the "safety efficiency", the higher the health and the safety of workers would be. If the managers and workers know the health risk precisely, they can 


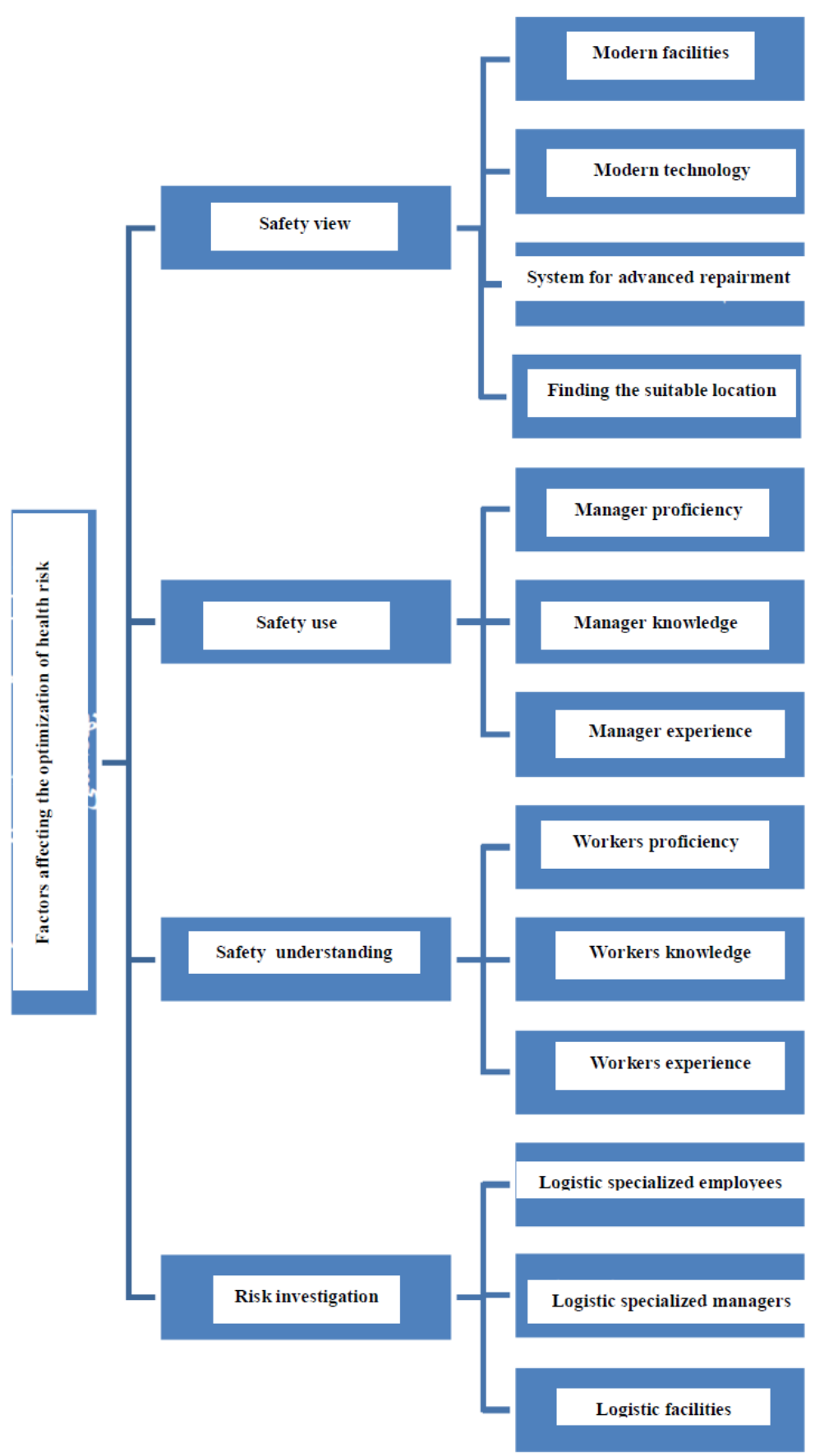

Figure 2. Network model to determine the optimization factors of the health risk

handle it more efficiently and take more effective measures to increase it during work [21, 22].

The different coefficients of models indicate that the effectiveness of "risk investigation" and "safety efficiency" is different in optimizing health risk depending on the level of investigation. Among the estimated results, one interesting result is the different effects of risk investigation on optimizing health risk [23]. According to the theoretical ideas, the correlation of "risk investigation" and "safety view" is a function of country risk investigation, which is in accordance with the results of the present research. Accordingly, research has indicated risk investigation results in the optimization of health risk; however, the effects are different with time, as it may also be negative [24-26].

The most important highlight of the study was the critical role of management in informing workers about the safety rules and compliance toward safety measures. 
Proper and timely safety training of the workers and equipping them with sophisticated safety equipment for daily activities are essential in ensuring a safe and healthy workplace environment [9]. Another study showed the possibility of fuzzy logic utilization in assessing safety, health, and environmental risk. It proposed a methodology based on the fuzzy-TOPSIS MCDM model for material selection suitable for the manufacturing sector. This method can produce a ranking result with strong reasonings [27].

The Philips-Perron test indicated that all variables were static. The fuzzy TOPSIS combined with the MODM confirmed the non-linear effect of risk investigation on optimizing health risk. The variables of the suggested models indicated that at the maximum and minimum levels of health risk, compared with the average levels, the "safety efficiency" was more significant on "safety view". The results confirmed the acceptability of the suggested and tested model [28].

\section{Conclusion}

The presented research shows that it is possible to investigate, prioritize and optimize the health risk of construction workers during work using the Multi-Objective Making Decision Method (MODM) combined with fuzzy TOPSIS to decrease any possible uncertainty. The significance of the present research is to increase the health and safety of workers during work resulting in a more sustainable and healthier environment. The findings are helpful for managers and workers because the findings increase the understanding of employees about the level of health risk and subsequently increase their level of safety. The results indicate that a method for investigating and optimizing health risk is required in each environment for better handling and managing the health environment. Accordingly, the managers could handle the risk, determine the tolerable risk, calculate the risk of each process to indicate the controlling expenses, and take the essential measures for optimization.

\section{Ethical Considerations}

\section{Compliance with ethical guidelines}

There were no ethical consideration to be considered in this research.

\section{Funding}

This study was supported by Ahvaz Branch of Islamic Azad University.

\section{Authors' contributions}

Conceptualization and study design, literature review, structuring, and development of the questionnaire, data analysis and interpretation, manuscript preparation, and edition: Eghbal Sekhavati; Study design, questionnaire preparation, review, editing, and project administration: Reza Jalilzadeh Yengejeh.

\section{Conflict of interest}

The authors declared no conflict of interest.

\section{Acknowledgments}

We express our gratitude and appreciation to the Deputy of Health, Islamic Azad University, Ahvaz Branch, and all the construction workers who accompanied us in this research.

\section{References}

[1] Hofmann DA, Burke MJ, Zohar D. 100 years of occupational safety research: From basic protections and work analysis to a multilevel view of workplace safety and risk. J Appl Psychol. 2017; 102(3):375-88. [DOI:10.1037/apl0000114] [PMID]

[2] Živković SB, Veljković MV, Banković-Ilić IB, Krstić IM, Konstantinović SS, Ilić SB, et al. Technological, technical, economic, environmental, social, human health risk, toxicological and policy considerations of biodiesel production and use. Renew Sust Energ Rev. 2017; 79:222-47. [DOI:10.1016/j. rser.2017.05.048]

[3] Perera F. Pollution from fossil-fuel combustion is the leading environmental threat to global pediatric health and equity: Solutions exist. Int J Environ Res Public Health. 2018; 15(1):16. [DOI:10.3390/ijerph15010016] [PMID] [PMCID]

[4] Li H, Wang J, Li R, Lu H. Novel analysis-forecast system based on multi-objective optimization for air quality index. J Clean Prod. 2019; 208:1365-83. [DOI:10.1016/j. jclepro.2018.10.129]

[5] Ali SS, Paksoy T, Torğul B, Kaur R. Reverse logistics optimization of an industrial air conditioner manufacturing company for designing sustainable supply chain: A fuzzy hybrid multi-criteria decision-making approach. Wirel Netw. 2020; 26:5759-82. [DOI:10.1007/s11276-019-02246-6]

[6] Ning X, Qi J, Wu C, Wang W. Reducing noise pollution by planning construction site layout via a multi-objective optimization model. J Cleaner Prod. 2019; 222:218-30. [DOI:10.1016/j. jclepro.2019.03.018]

[7] Bayat M, Asil AG. Efficient in-situ water adsorption for direct DME synthesis: Robust computational modeling and multi-objective optimization. J Nat Gas Sci Eng. 2020; 83:103587. [DOI:10.1016/j.jngse.2020.103587] 
[8] Feng J, Gong Z. Integrated linguistic entropy weight method and multi-objective programming model for supplier selection and order allocation in a circular economy: A case study. J Clean Prod. 2020; 277:122597. [DOI:10.1016/j. jclepro.2020.122597]

[9] Singh A, Misra SC, Kumar V, Kumar U. Identification and ordering of safety performance indicators using fuzzy TOPSIS: A case study in Indian construction company. Int J Qual Reliab Manag. 2021 [In Press]. [DOI:10.1108/ IJQRM-02-2020-0051]

[10] Singh KR, Dutta R, Kalamdhad AS, Kumar B. Risk characterization and surface water quality assessment of Manas River, Assam (India) with an emphasis on the TOPSIS method of multi-objective decision making. Environ Earth Sci. 2018; 77(23):780. [DOI:10.1007/s12665-018-7970-9]

[11] Dabbagh R, Yousefi S. A hybrid decision-making approach based on FCM and MOORA for occupational health and safety risk analysis. J Safety Res. 2019; 71:111-23. [DOI:10.1016/j. jsr.2019.09.021] [PMID]

[12] Chen TY, Tsao CY. The interval-valued fuzzy TOPSIS method and experimental analysis. Fuzzy Sets Syst. 2008; 159(11):1410-28. [DOI:10.1016/j.fss.2007.11.004]

[13] Jalilzadeh R, Rahmani MS. [Risk assessment of suspended particles using EFMEA technique and TOPSIS method in District 9 of Tehran Municipality (Persian)]. J Environ Sci Technol. 2021; 23(2):275-94. [DOI:10.22034/JEST.2019.30498.3902]

[14] Jalilzadeh, R., Ghodusi, J., seedshamsi, M. Identifying and ranking the factors influencing the development and construction waste management in urban areas using FAHP. J Environ Sci Technol. 2018 [In Press]. [DOI:10.22034/ JEST.2018.11536.2037]

[15] Zhang F, Ju Y, Santibanez Gonzalez EDR, Wang A, Dong $\mathrm{P}$, Giannakis M. Evaluation of construction and demolition waste utilization schemes under uncertain environment: A fuzzy heterogeneous multi-criteria decision-making approach. J Clean Prod. 2021; 313:127907. [DOI:10.1016/j. jclepro.2021.127907]

[16] Li X, Yi W, Chi HL, Wang X, Chan APC. A critical review of virtual and augmented reality (VR/AR) applications in construction safety. Autom Constr. 2018; 86:150-62. [DOI:10.1016/j.autcon.2017.11.003]

[17] Wang D, Wang X, Xia N. How safety-related stress affects workers' safety behavior: The moderating role of psychological capital. Saf Sci. 2018; 103:247-59. [DOI:10.1016/j. ssci.2017.11.020]

[18] Wen Z, Liao H, Zavadskas EK, Antuchevičienė J. Applications of fuzzy multiple criteria decision making methods in civil engineering: A state-of-the-art survey. J Civ Eng Manag. 2021; 27(6):358-71. [DOI:10.3846/jcem.2021.15252]

[19] Rolison JJ, Morsanyi K, Peters E. Understanding health risk comprehension: The role of math anxiety, subjective numeracy, and objective numeracy. Med Decis Making. 2020; 40(2):22234. [DOI:10.1177/0272989X20904725] [PMID] [PMCID]

[20] Baldwin C, Rawstorne P. Public understanding of risk in health impact assessment: A psychosocial approach. Impact Assess Proj Apprais. 2019; 37(5):382-96. https://www.scilit. net/article/f14a4c4175f9c53585003936abffbdd1
[21] Thibaud M, Chi H, Zhou W, Piramuthu S. Internet of Things (IoT) in high-risk Environment, Health and Safety (EHS) industries: A comprehensive review. Decis Support Syst. 2018; 108:79-95. [DOI:10.1016/j.dss.2018.02.005]

[22] Shestopalova T, Gololobova TV. Standard operating procedures as a trend in ensuring healthcare safety. Health Risk Anal. 2018; 2018(2):129-37. [DOI:10.21668/health. risk/2018.2.15.eng]

[23] Liu HC. Improved FMEA methods for proactive healthcare risk analysis. New York: Springer; 2019. [DOI:10.1007/978981-13-6366-5]

[24] Qasemi M, Afsharnia M, Zarei A, Farhang M, Allahdadi M. Non-carcinogenic risk assessment to human health due to intake of fluoride in the groundwater in rural areas of Gonabad and Bajestan, Iran: A case study. Hum Ecol Risk Assess: Int J. 2018; 25(9):1-12. http:/ / eprints.gmu.ac.ir/414/

[25] Tong R, Zhang L, Yang X, Liu J, Zhou P, Li J. Emission characteristics and probabilistic health risk of volatile organic compounds from solvents in wooden furniture manufacturing. J Clean Prod. 2019; 208:1096-108. [DOI:10.1016/j. jclepro.2018.10.195]

[26] Hansen OR. Hydrogen infrastructure-Efficient risk assessment and design optimization approach to ensure safe and practical solutions. Process Saf Environ Prot. 2020; 143:164-76. [DOI:10.1016/j.psep.2020.06.028]

[27] Khalilzadeh M, Balafshan R, Hafezalkotob A. Multi-objective mathematical model based on fuzzy hybrid multicriteria decision-making and FMEA approach for the risks of oil and gas projects. J Eng Des Technol. 2020; 18(6):1997-2016. [DOI:10.1108/JEDT-01-2020-0020]

[28] Rahim AAA, Musa SN, Ramesh S, Lim MK. Development of a fuzzy-TOPSIS multi-criteria decision-making model for material selection with the integration of safety, health and environment risk assessment. Proc Inst Mech Eng L. 2021; 235(7):1532-50. [DOI:10.1177/1464420721994269] 
This Page Intentionally Left Blank 